\title{
A new concept of orthosis for correcting fingers ulnar deviation
}

\author{
Daniela Nakandakari Goia ${ }^{1}$, Carlos Alberto Fortulan², Benedito Moraes Purquerio², \\ Valéria Meirelles Carril Elui ${ }^{1,3 *}$
}

\author{
${ }^{1}$ Inter-units Postgraduate Program in Bioengineering, School of Engineering, University of São Paulo, São Carlos, SP, Brazil. \\ ${ }^{2}$ Department of Mechanical Engineering, School of Engineering, University of São Paulo, São Carlos, SP, Brazil. \\ ${ }^{3}$ Department of Neuroscience and Behavioral Sciences, Ribeirão Preto Medical School, University of São Paulo, \\ Ribeirão Preto, SP, Brazil.
}

\begin{abstract}
Introduction: Rheumatoid arthritis (RA) is a chronic, multisystem disease that involves synovial inflammation, leading to deformities, like finger ulnar deviation, pain and functional difficulties. The conservative treatment comprises orthoses, features added to the body that aims to correct deformity, reduce pain and improve functionality. In the market there are few kinetic/mobile orthosis models for correction of ulnar deviation in the fingers. However, users usually complain about increased palmar volume, presence of pressure points and functional loss, demonstrating the necessity to develop more effective orthoses. In this paper we introduce an innovative concept, of an original and articulate dynamic/kinetics orthosis, which aims to correct this finger deformity and encourage functionality. Methods: Methodological procedures were divided into: Need Recognition; Specification Concept; Prototype and Validation. This paper deals with the last two stages of this research. Results: A virtual orthosis prototype using CAD Solid Edge Insight ${ }^{\mathrm{TM}}$ was proposed. The orthosis developed consisted of 10 pieces, made of metal and resin with carbon fiber. Conclusion: After virtual movement simulation, it was verified that the prototype allows for wrist and finger flexion/extension, the possibility of bilateral use, and provids ulnar deviation correction for the fingers. The final product is innovative and is easy to put on/off; volunteers claimed that the new prototype was satisfactory in terms of deformity correction.
\end{abstract}

Keywords Rheumatology, Deformity, Innovation, Orthotic devices, Functioning, Rehabilitation.

\section{Introduction}

Rheumatoid arthritis (RA) is a chronic, multisystem disease that affects the individual as a whole, has unknown etiology, and because of persistently and cumulative synovial joint inflammation causes a deleterious effect on periarticular structures, leading to joint pain and deformities (Skare, 1999). Usually, in the acute phase, the patients feels the disease's effects in their hands and upper extremities (swelling, joint pain and morning stiffness) causing major impact on functional abilities (Vliet Vlieland et al., 1996).

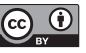

This is an Open Access article distributed under the terms of the Creative Commons Attribution License, which permits unrestricted use, distribution, and reproduction in any medium, provided the original work is properly cited.

How to cite this article: Goia DN, Fortulan CA, Purquerio BM, Elui VMC. A new concept of orthosis for correcting fingers ulnar deviation. Res Biomed Eng. 2017; 33(1):50-57. DOI: 10.1590/2446-4740.02516

*Corresponding author: Faculdade de Medicina de Ribeirão Preto, Universidade de São Paulo - USP, Avenida Bandeirantes, 3900, Monte Alegre, CEP 14049-900, Ribeirão Preto, SP, Brazil. E-mail: velui@fmrp.usp.br

Received: 19 April 2016 / Accepted: 17 February 2017
The normal hand has a balance between static and dynamic forces generated by an integrated operation between the muscles fibers, the tendon system, the bones and the joint structures, what is affected by the deformities in the metacarpophalangeal joints (MPs), interphalangeal joints (IPs) and wrist (Lede and Veldhoven, 2002). The pathophysiology deformity starts with the inflammation of the synovium, which can result in capsular distension with cartilage destruction, the presence of subchondral erosion, the loss of ligamentous insertion with consequent joint disorganization, and loss of tendon sliding function (Callinan, 2005). Finger ulnar deviation deformity (FUD) begins with the destruction of the wrist ligaments that move towards radial deviation. Using body compensatory mechanisms, the excessive forces are transferred to the fingers' extensor tendons. This force favors the collapse of the finger extensor tendons on the ulnar side and leads to subluxation/dislocation of the first phalanx ventrally and to the flexion contracture of MPs, resulting in the ulnar deviation deformity (Golding, 2001). The deformity progression is also favored by deforming forces triggered by external pressures (handling objects with movements in the ulnar direction) and/or internal 
forces (muscle imbalances), favoring the worsening of the deformity with a loss of grasp capacity and a lack of metacarpophalangeal extension (Noordhoek and Barbosa, 2004).

\section{Orthoses and $R A$}

Tijhuis et al. (1998) recommends the use of orthoses in conservative treatment for RA. Orthoses are external devices applied to any part of the body to stabilize or immobilize it, prevent or correct deformities, protect against injury, maximize function and reduce the pain caused by deformity (Assumpção, 2005; Deshaies, 2005; Schuch and Pritham, 1994). The main function of orthosis is to optimize the locomotor system through external force that influences joint mobility. The orthosis is an important resource for the treatment of musculoskeletal disorders, assisting in getting early results, shortening the treatment time, reducing tissue stress and restoring and enhancing the function of the upper extremities.

The device construction relies on mechanical engineering principles that enhance comfort and efficacy, promoting a proper and well suited resource. Generally, they act as a first-class lever system, with three points of acting force, and also distribute the pressure (Luzo et al., 2004).

Orthoses are tailor-made by therapists, using mainly low temperature thermoplastic material. There are different types of thermoplastic materials, which can have different rubber concentrations in their polymer composition. These different concentrations lead to differences in rigidity, deformation capability, texture, memory, adhesion and finishing, and color, factors that the therapist has to consider when building an orthotic device (Callinan, 2005).

\section{Orthoses mechanics and classification}

There are several orthosis designs used in our clinical practices to correct FUD that varies according to patient's need and therapist design preference. Figure 1 shows different designs, like (A) one ventral static orthosis that is indicated for day usage when the patient has a passive lack of metacarpophalangeal extension, that at the same time corrects the deformity, helps to maintain a functional extension for daily use. One of the most commonly used orthoses best used at night is the orthosis in rest functional position (forearm, wrist and fingers - B), others designs for daily use are ventral and dorsal construct with fabric (C), dorsal with dynamic extension (D), ventral and dorsal with elastic traction (E), or ventral wrist stabilization with elastic traction $(\mathrm{F})$.

The design begins with the knowledge of the physical laws that direct the construction and function of the device through the applied forces. The main function of orthoses is to optimize the locomotor system, but first of all we must consider the pathological necessity, use physical and physiological principles, and thus specify the anatomical adaptations and individual functions. To create the orthosis, gravity and action and reaction forces also need to be taken into account (Lede and Veldhoven, 2002). The static device does not allow for movement, while the dynamic device requires greater patient involvement because by definition it is a device that initiates or promotes movement. The dynamic orthosis has elements that permit or facilitate motion
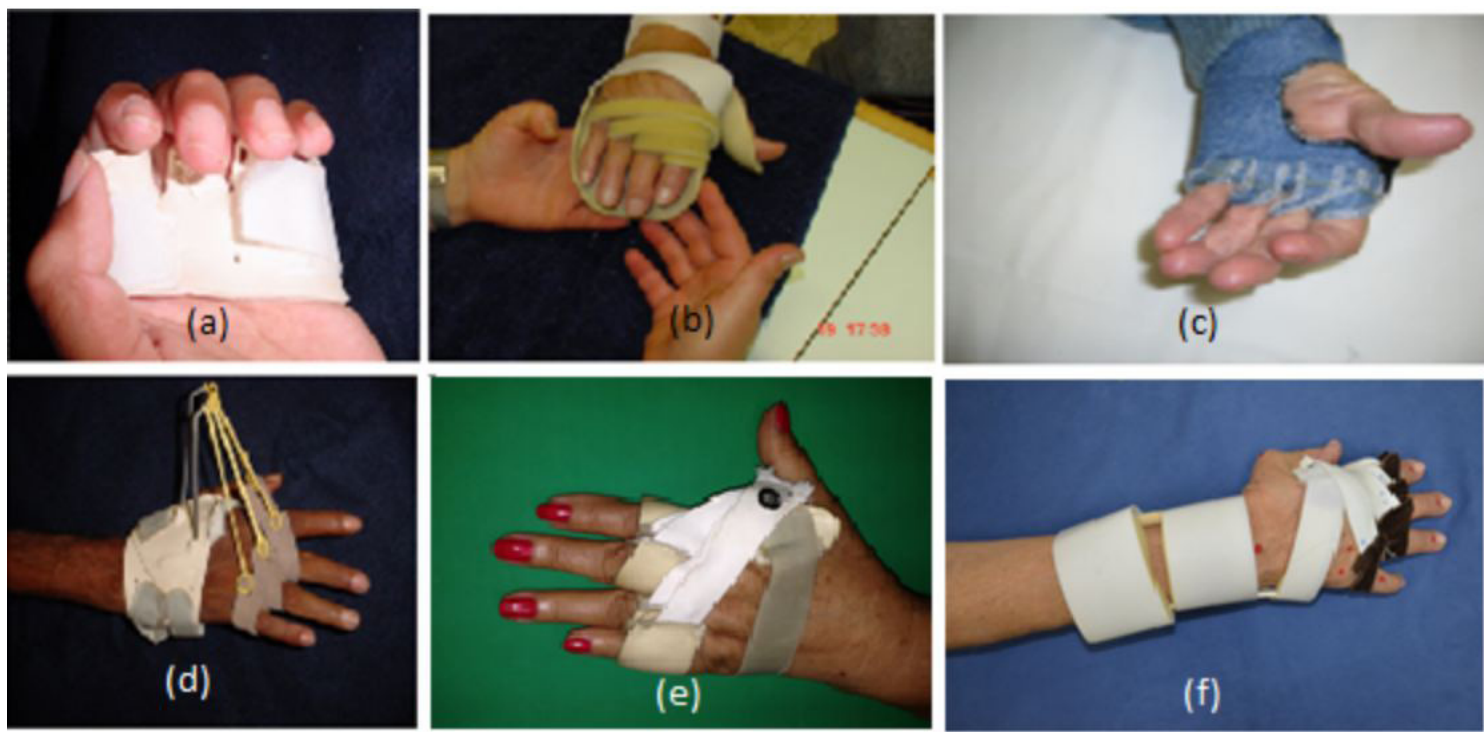

Figure 1. (a) Thermoplastic ventral orthosis; (b) Wrist hand orthosis; (c) Fabric orthosis; (d) High profile hand orthosis; (e) Elastic traction orthosis (f) Wrist orthosis and elastic traction. Types of orthoses for ulnar deviation correction for the fingers. Source: Elaborated by the author. 
through the applied external force in order to hinder tissue deformation, restore or replace lost movements and provide an autonomous power source.

Lede and Veldhoven (2002) emphasize that there is, beyond the dynamic orthosis, another classification based on kinetics theory. The movement, in this case, is initiated by the body segments that allow the continuation of the joint movement. The distinction is made between linear and circular motion. These are related to the orthoses that have hinges (joints), which allows movement to be actively initiated by the patient. It has no independent source of power, and thus cannot be called dynamic but mobile or kinetic. Most often mobile or kinetic orthoses are used to selectively exclude certain standard (pathological) movements and let other movements happen via the patient's muscle force; in some cases, they could redirect that force to promote function.

Rennie (1996) describes a side hinge orthosis for ulnar deviation correction, and achieved a significant third, fourth and fifth finger correction of the ulnar deviation. According to the patient, this device did not prevent the performance of functional activities.

In our clinic practice we often face patient's complaints regarding the design of the custom-made thermoplastic orthosis, appointing: presence of pressure points that cause pain and great palmar volume that correlates to be a negative effect in terms of functionality, as also appointed by Vliet Vlieland et al. (1996).

The aim of this study is the development of an innovative concept model of orthosis that allows deformity correction with comfort, allows function and is easy to clean, put on and take off. This study was inspired by the disease's functional limitations and the patient's functional difficulties.

\section{Methods}

The study was divided into four stages, following Asimow (1964). The first stage, called Need recognition, was based on the literature review, therapist clinical observations regarding the use of orthoses for FUD correction and patients' opinion of the devices. The second stage - Specification - was based on the existing orthoses model with anthropometric measures and mechanical efforts study. The third stage is linked to Conceptualization, when the orthosis design and parts measures are defined; the fourth stage is the Prototype development. This article is shall describe the results of the third and fourth stages of this research.

\section{Stage 1: need recognition}

Aiming to make the prevention and/or correction of the deformity and based on the pathophysiology, the purpose of the new concept orthosis for FUD correction should be to prevent or correct carpal bone subluxation, MP subluxation (palmar) and loss of MP extension. If there is an attempt to place orthosis in a way that applies too much force at the proximal phalanges of the fingers, the force applied on soft tissues may cause pressure problems and consequent pain. Moreover, in more advanced stiff deformity of MPs, a surgical procedure is recommended (Golding, 2001).

The literature shows few studies about orthosis development/use for FUD correction. There is also no innovation in the orthosis design, as well as no differentiation in the materials used in the manufacture (Malcus Johnson et al., 1992; Noordhoek and Loschiavo, 2007).

It was noted in our clinic practice that the existing orthosis can perform deformity correction (with a focus on the mechanical functions); this could be partial in some cases, but does not include or promote the user's functional needs, especially regarding hand volume or pain reduction (hand and wrist), what leads to the importance to develop a new orthosis design.

\section{Stage 2: specification}

This phase of the project involved the development of a pre-project focusing on the needs for the development of the product through hand anthropometric literature reviews (Minetti et al., 2002; Paschorelli and Menezes, 2009; Rodrigues, 2010). We found from these studies that there were no differences in the measures presented in palm, wrist and fingers sizes with the researcher's hand antropometric measurement, making possible to use this hand as a reference, and thus determine the dimensions of the parts of the orthosis. This step involved the pre-conceptual and informational stage of development of the orthosis with the definition of models for the composition of the parts.

\section{Results}

The design concept was based on need recognition, specification, biomechanical concepts and their application to the wrist, MP and finger alignment requirements, the concept model was manufactured as a prototype and validated with patients followed by optimizations.

\section{Stage 3: concept}

The design conceived is composed of bars with lateral fixation on the forearm and wrist, placed on the lateral aspect of the fifth metacarpal (palm of the hand) and the proximal fifth finger phalanx. All the parts are articulated to allow wrist and finger flexion and extension. Its design aims at a better pressure distribution in all areas of the hand and forearm. It must be slim in order to achieve low weight and allow for the concurrent use 
of all fingers, and also to be cosmetically acceptable and to present low palmar volume to enhance function.

The sketch design (Figure 2) was developed to deal with the deformity physiopathology (starts at the wrist) and user's frequent complaints about pain caused by correction traction, and the increased palmar volume that leads to functionality loss, plus the difficulty in using the orthosis during normal activities. Based on the literature, patient's complaint needs regarding usability, following the concepts of developing an orthosis and associated with the clinical experience of the researchers, this model was developed.

\section{Stage 4: prototype}

To achieve the optimized prototype design, the first prototype was designed from the stages above and after the handwritten prototype, using as reference

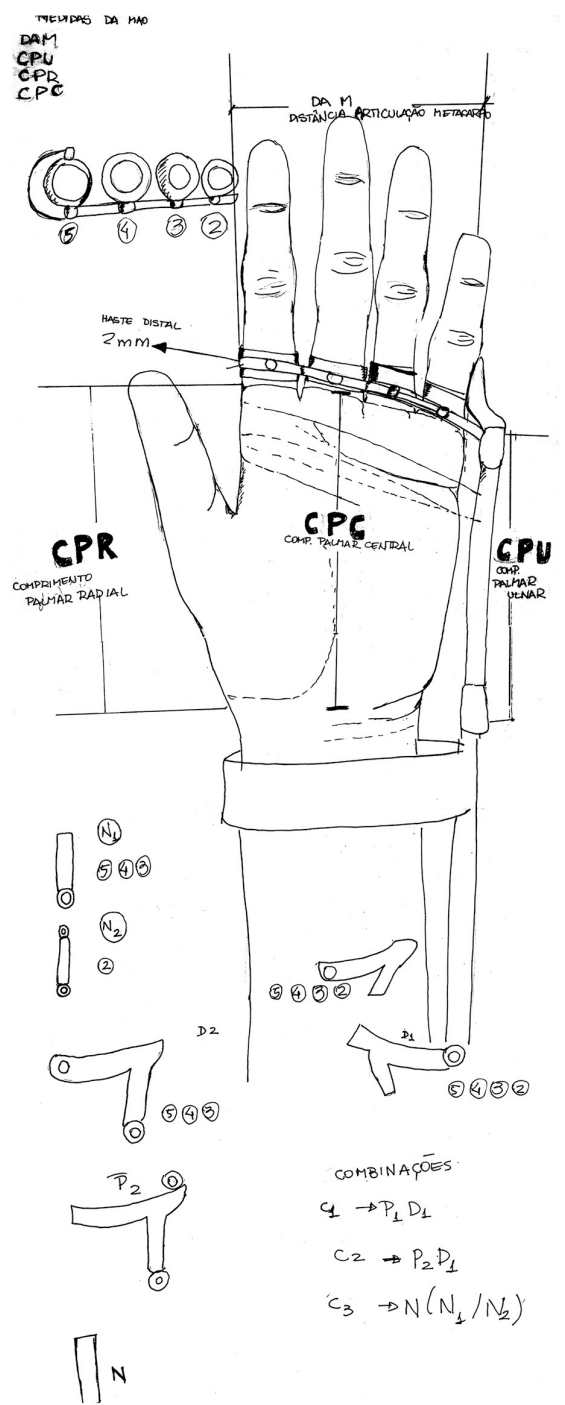

the researcher's hand measurements (following the anthropometry of a median hand), considering the degree of joint movement, finger diameter, palm wrist and forearm circumferences, as well as the palmar creases line (which determines the range of hand motion), the design was reproduced using the CAD Solid Edge Insight TM program (Figure 3), making it possible to perform virtual movement simulation, verify the concept design restrictions and make the necessary design corrections for better virtual function, valuing the researchers expertise.

After defining the measures, the prototype design was developed using CAD Solid Edge Insight ${ }^{\mathrm{TM}}$. The final product consists of 10 pieces: two side bars (for forearm and palm), an ulnar blocking ring, three semi-circular rings for the second, third and fourth fingers, three bracelets (forearm, wrist and palm) and a metal wire to fix the rings.

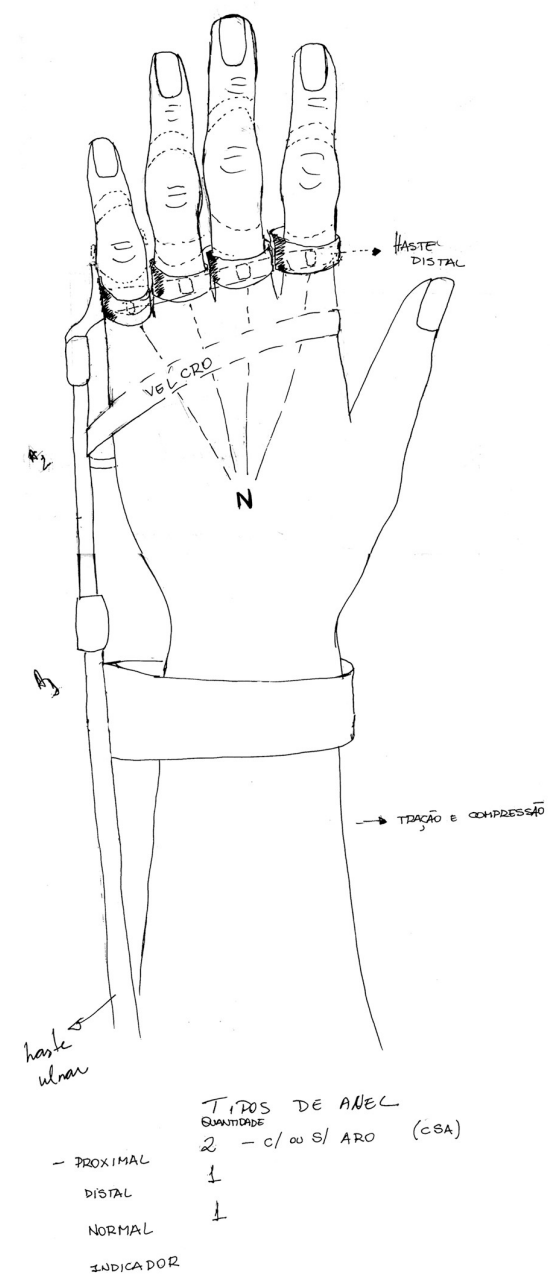

Figure 2. Sketch of the prototype. 
Other than the bars, the pieces were made of plaster; the first step was to print them on an inkjet plaster printer Z Printer $310-Z$ Corporation. The pieces were printed separately for better viewing and assessment (Figure 4).

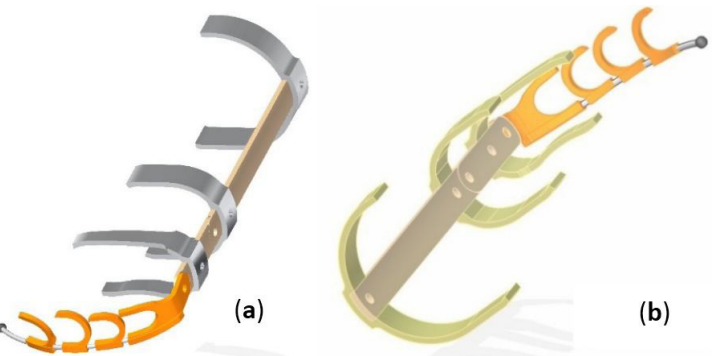

Figure 3. Prototype CAD Solid Edge Insight ${ }^{\mathrm{TM}}$ : (a) Frontal view; (b) Back view.

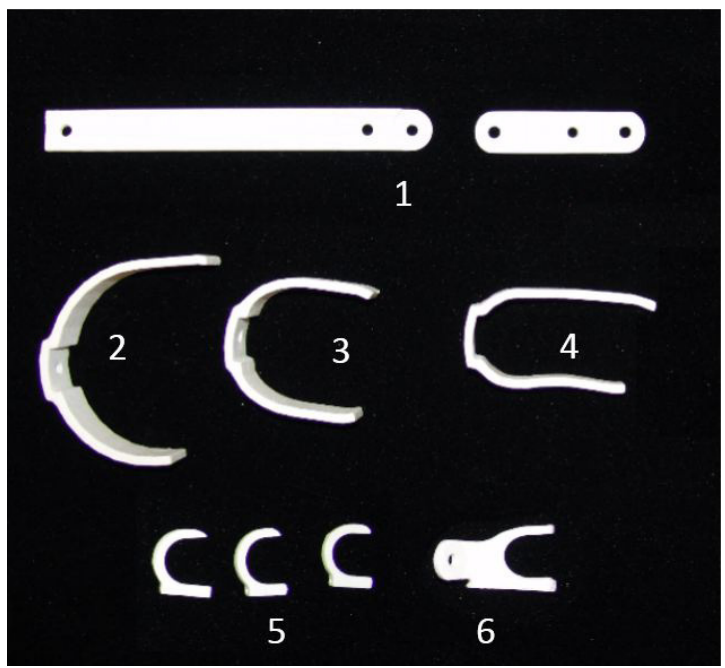

Figure 4. Printed plaster parts: (1) Side bars; (2) Forearm bracelet; (3) Wrist bracelet; (4) Palmar bracelet; (5) Semi-circular rings; (6) Ulnar block rings.
From the plaster model was made a negative mold of the parts with silicone (P364A). The mold was cast separately for each part (Figure 5).

For the parts manufacturing it was mixed two-component of Polyurethane Resin Thermoset (Fillepoxi), cast into the silicone mold cavities.

Initially, the lateral bars were made of resin. However, during the bench testing with the researchers, there was a need to make them more resistant and rigid, and carbon fiber was added into the resin; further stability was required, and the bars ended up being made of machined metallic pipes. The metal wire fixes the blocking ring and the rings. The orthosis was fixed to the patient's limb with velcro strap to the bracelets. The concept of the orthosis was successful in the idealization and production of prototype what is demonstrated in Figure 6.

Following the Research Ethics Committee (process HCRP No. 14599/2011) approval, the prototype was developed and then used during 3 consecutive days for at least 8 waking hours by the researchers to verify safety and function. Afterwards optimizations were performed on the design that was used one more time by the researchers. When it was functioning properly, the prototype was tested by three patients/volunteers, two females and one male aged from 46 to 65 years with deformity in at least one hand, which also used for at least 3 months a thermoplastic orthosis handmade by the therapist. All of then agreed to participate and signed the informed and free consent agreement.

The transversal study methodology consisted of a single assessment in the clinical setting. They had their FUD joints measured (goniometry) with and without the orthosis, performed some predetermined function (pen, glass, scissor, wallet in the purse and screw/unscrew small pot). They then answered an open questionnaire giving their opinion about the new orthosis; this contained questions about appearance,
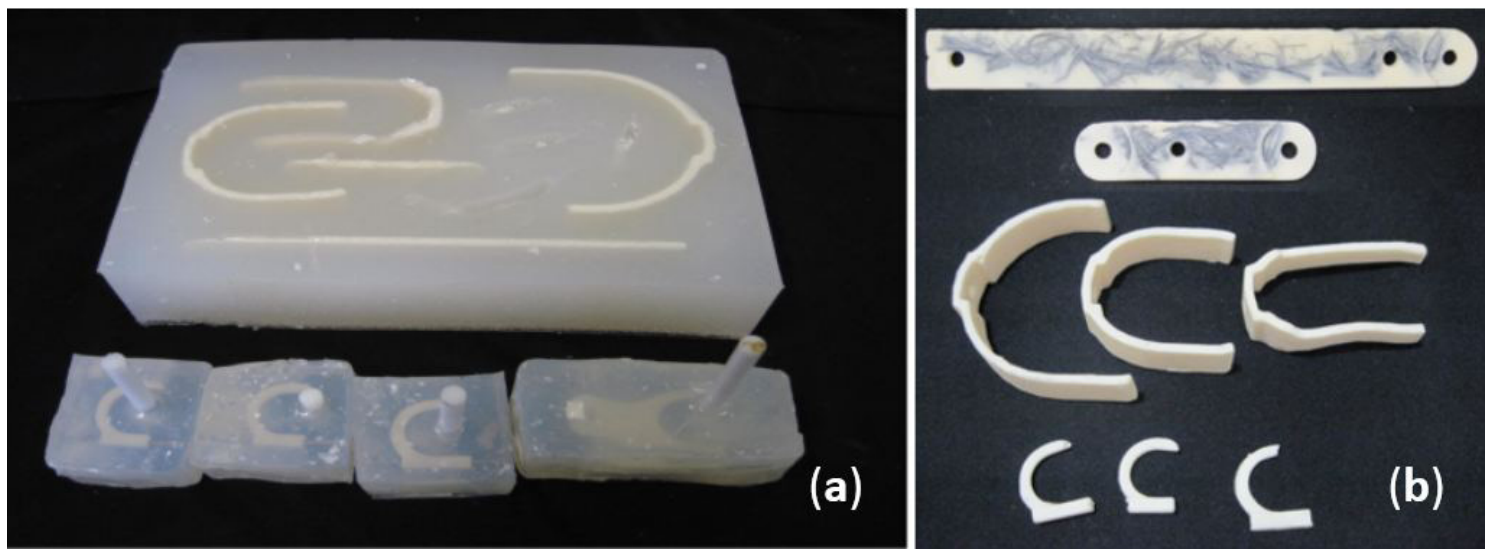

Figure 5. Casting process: (a) Silicone mold filled; (b) Resin parts. 
possible movements, way to put it on and take it off, and the functional use of the hand.

To verify the safety of the orthosis and its functional performance, virtual motion simulation of flexion and extension movements was performed using CAD Solid Edge. The concept of the orthosis prototype was proven to be effective in maintaining the fingers with no deviation and at the same time allowing flexion and extension movements in both metacarpophalangeal and wrist articulations.

The concept and its prototype has given a favorable and satisfactory result regarding deformity correction

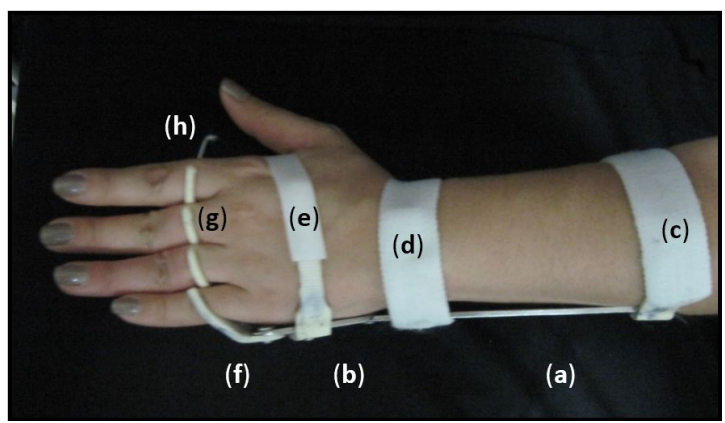

Figure 6. Assembled prototype: (a) Forearm bar; (b) Palmar side bar; (c) Forearm bracelet; (d) Wrist bracelet; (e) Palmar bracelet; (f) Ulnar block; (g) Rings; (h) Wire stem. and made it possible to use the full flexion and extension movements for the fingers and wrist.

\section{Prototype validation}

The volunteers tested the new orthosis for about one hour and according to their opinions, the new orthosis is lighter, allows better mobility, correct the deformity in a comfort way, enables function, is more aesthetically pleasing and is easy to put on and take off compared with the conventional orthosis to correction the ulnar deviation that they were wearing. Figure 7 demonstrates a volunteer picking up an object and the difference in the positioning of the fingers in deviation with and without the orthosis can be noted.

Wrist alignment as well as the MPs was observed with the goniometric measurements, Table 1.

According to data in Table 1, the average finger ulnar deviation correction was $41.2 \%$ as well as $100 \%$ correction of the radial deviation of the wrist. The material appeared resistant and showed no misalignment or deformation during testing.

This innovative orthosis was published with patent number INPI (National Institute of Industrial Property): BR 102013 019730-0 A2 in 09/22/2015 at Industrial Property Magazine RPI nº. 2333, page. 71, item 3.1.
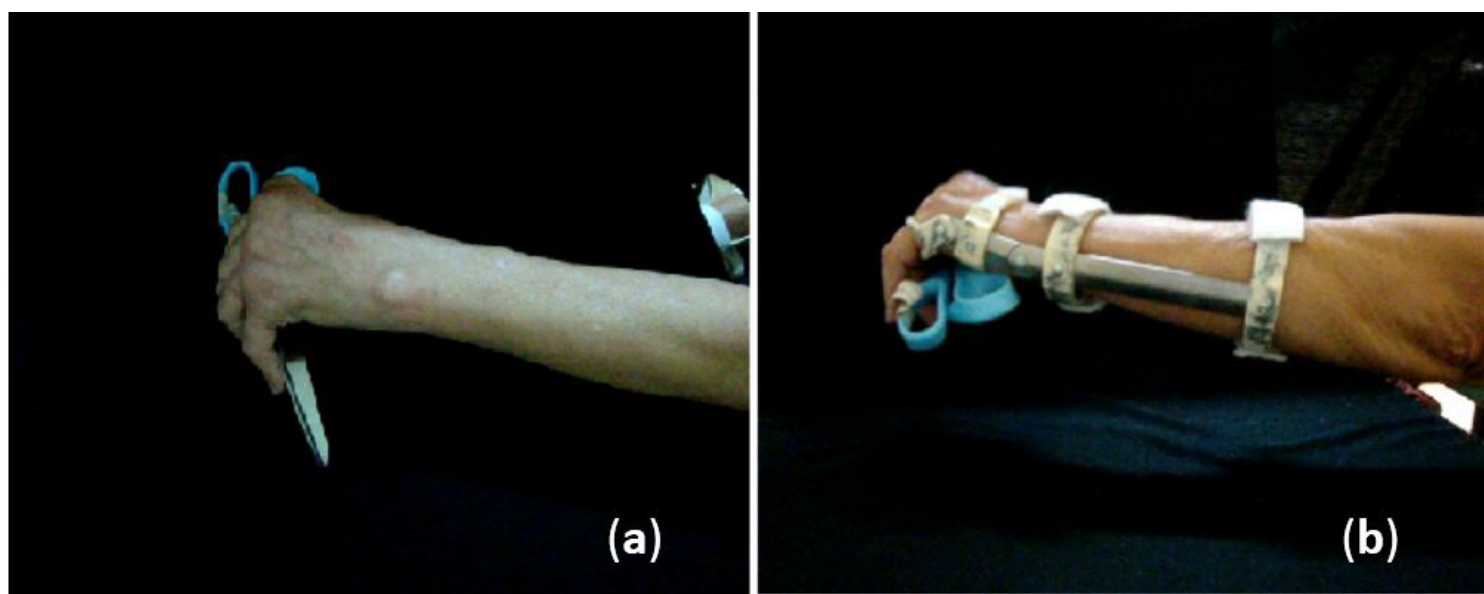

Figure 7. Volunteer 2 picking up scissors: (a) Without the orthosis; (b) With the orthosis.

Table 1. Goniometric measures average with and without orthosis and the percentage of correction.

\begin{tabular}{|c|c|c|c|c|c|c|c|c|c|}
\hline \multirow{3}{*}{$\begin{array}{c}\text { Goniometry } \\
\text { Subject }\end{array}$} & \multicolumn{9}{|c|}{ Left hand } \\
\hline & \multicolumn{3}{|c|}{ Without orthosis } & \multicolumn{3}{|c|}{ With orthosis } & \multicolumn{3}{|c|}{ Correction (\%) } \\
\hline & $\mathbf{A}$ & B & $\mathbf{C}$ & $\mathbf{A}$ & B & $\mathbf{C}$ & $\mathbf{A}$ & B & $\mathbf{C}$ \\
\hline Wrist radial deviation & $0^{\circ}$ & $14^{\circ}$ & $0^{\circ}$ & $0^{\circ}$ & $0^{\circ}$ & $0^{\circ}$ & - & 100 & - \\
\hline $2^{\text {nd }}$ finger ulnar deviation & $10^{\circ}$ & $30^{\circ}$ & $0^{\circ}$ & $8^{\circ}$ & $15^{\circ}$ & $0^{\circ}$ & 20 & 50 & - \\
\hline $3^{\text {rd }}$ finger ulnar deviation & $20^{\circ}$ & $30^{\circ}$ & $12^{\circ}$ & $18^{\circ}$ & $20^{\circ}$ & $6^{\circ}$ & 20 & 29 & 50 \\
\hline $4^{\text {th }}$ finger ulnar deviation & $14^{\circ}$ & $34^{\circ}$ & $14^{\circ}$ & $12^{\circ}$ & $22^{\circ}$ & $2^{\circ}$ & 20 & 35 & 85.7 \\
\hline $5^{\text {th }}$ finger ulnar deviation & $30^{\circ}$ & $34^{\circ}$ & $12^{\circ}$ & $20^{\circ}$ & $18^{\circ}$ & $4^{\circ}$ & 30 & 47 & 66.7 \\
\hline
\end{tabular}




\section{Discussion}

Santosh (2011) point out that pathological conditions of the hand results in function loss or limitation due to deformities, stiffness, inadequate power and poor finger positioning for pinching. That mobility, stability and strength are the three prerequisites for prehensile hand function and function difficulties arise when any of the three components of the working hand are affected. With this new concept of a long articulated kinetic orthosis to correct finger ulnar deviation, it is possible to improve functionality with more aligned wrist and fingers movements according to the measurements of deformity correction (Table 1).

Bielefeld and Neumann (2005, p. 153) stated

It is, however, a challenge to design a splint that simultaneously blocks radial deviation of the wrist while not compromising the effectiveness of blocking ulnar drift at the MCP joints, and vice versa.

This orthosis concept gives support to the wrist blocking the radial deviation of the wrist, correct the ulnar deviation of the fingers and do not limit wrist and fingers flexion/extension movements, having the capacity to improve patients' hand function and quality of life.

Regarding patient's opinions about the current design orthotics devices for ulnar deviation of the fingers correction that is indicated in the service, discomfort and loss of function are the problems encountered in current treatment, what is also stated by Bielefeld and Neumann (2005).

The new concept developed through the patient's opinion and acceptance of the prototype demonstrated to be able to exert enough strength for the deformity correction in a comfortable way, with little thickness and palmar volume, allowing hand function and the design allowed its use in both hands.

No studies correlating the use of orthotics for ulnar deviation correction of the fingers that encompass the wrist and fingers movement have been done, but what was observed during interviews with patients is that the concept and its prototype were given a favorable and satisfactory result regarding deformity correction and also made possible the use and movement of the hand during activities. In the opinion of the patients there was a greater comfort as the coupling and its use during activities.

Although the concept has been a success, this orthosis development implemented the design thinking that leads to the future studies like design evolution aiming to optimize the design to decrease pressure in the phalanges (finger) and improve it with: more deformity correction; more comfort; aesthetics and also test it through larger population.

\section{Acknowledgements}

We acknowledge the cooperation of the Rehabilitation Center of the Clinical Hospital -Medical Faculty of Ribeirao Preto University of Sao Paulo (CER-HCFMRP/USP), the Mechanical Department of the Sao Carlos Engineering School - University of Sao Paulo (EESC-USP), and the Bioengineering Interunit Post-graduation Program (EESC/FMRP/IQSC-USP).

We would like to thank Luiz Adalberto Penazzi for his support during the orthosis prototype development and the volunteers for their interest, availability and cooperation during the test process. Financial Support: FAPESP process 2014/50022-3.

\section{References}

Asimow M. Introduction to design: fundamentals of engineering design. 2th ed. Upper Saddle River: Prentice-Hall; 1964.

Assumpção TS. Órteses: princípios básicos. In: Freitas PP, editor. Reabilitação da mão. São Paulo: Atheneu; 2005. p. 539-54.

Bielefeld T, Neumann DA. The unstable metacarpophalangeal joint in rheumatoid arthritis: anatomy, pathomechanics, and physical rehabilitation considerations. The Journal of Orthopaedic and Sports Physical Therapy. 2005; 35(8):502-20. PMid:16187511. http://dx.doi.org/10.2519/jospt.2005.35.8.502.

Callinan N. Confecção de órtese para mão. In: Trombly CA, Radomsky MV, editors. Terapia ocupacional para as disfunções físicas. 5th ed. São Paulo: Santos; 2005. p. 351-70.

Deshaies ID. Órteses para membro superior. In: Trombly CA, Radomski MV, editors. Terapia ocupacional para disfunções físicas. 5th ed. São Paulo: Santos; 2005. p. 313-49.

Golding DN. Reumatologia em medicina e reabilitação. São Paulo: Atheneu; 2001. p. 83-100.

Lede PV, Veldhoven GV. Therapeutic hand splints: a rational approach. Gilroy: North Coast Medical; 2002. v. 2, p. 96-108.

Luzo MCM, Mello MAF, Capanema VM. Recursos tecnológicos em terapia ocupacional: órteses e tecnologia assistiva. In: De Carlo MMRP, Luzo MCM, editors. Terapia ocupacional: reabilitação física e contextos hospitalares. São Paulo: Roca; 2004. p. 99-126.

Malcus Johnson P, Sandkvist G, Eberhardt K, Liang B, Herrlin $\mathrm{K}$. Usefulness of nocturnal resting splints in the rheumatoid treatment of ulnar deviation of the hand. Journal of Clinical Rheumatology; Practical Reports on Rheumatic \& Musculoskeletal Diseases. 1992; 11(1):72-5. PMid:1582123.

Minetti LJ, Souza AP, Alves JU, Fiedler NC. Estudo antropométrico de operadores de motosserra. Revista Brasileira de Engenharia Agrícola e Ambiental. 2002; 6(1):166-70. http:// dx.doi.org/10.1590/S1415-43662002000100029.

Noordhoek J, Barbosa LF. Órtese de jeans para desvio ulnar dos dedos. Revista Brasileira de Reumatologia. 2004; 44(2):150-1. PMid:21503540. http://dx.doi.org/10.1590/ S0482-50042004000200007. 
Noordhoek J, Loschiavo FQ. Órtese de repouso para fase aguda de artrite reumatóide. Revista Brasileira de Reumatologia. 2007; 47(2):121-2. http://dx.doi.org/10.1590/ S0482-50042007000200007.

Paschorelli LC, Menezes MS. Design e ergonomia: aspectos tecnológicos. São Paulo: Cultura Acadêmica; 2009.

Rennie HJ. Evaluation of effectiveness of metacarpophalangial ulnar deviation orthosis. Journal of Hand Therapy. 1996; 9(4):371-7. PMid:8994013. http://dx.doi.org/10.1016/S08941130(96)80044-5.

Rodrigues MCR. Desenvolvimento de uma órtese articulada para correção de deformidade em pescoço de cisne [dissertation]. Ribeirão Preto: University of São Paulo; 2010. 111 p.

Santosh R. Hand kinematics: application in clinical practice. Indian Journal of Plastic Surgery: Official Publication of the
Association of Plastic Surgeons of India. 2011; 44(2):178-85. PMid:22022027. http://dx.doi.org/10.4103/0970-0358.85338.

Schuch CM, Pritham CH. International forum: international standards organization terminology: aplication to prosthetics and orthotics. Journal of Prosthetics and Orthotics. 1994; 6(1):29-33.

Skare TL. Reumatologia: princípios e prática. 2nd ed. Rio de Janeiro: Guanabara Koogan; 1999. p. 91-104.

Tijhuis GJ, Vliet Vlieland TPM, Zwinderman A, Hazes JMH. A Comparison of the Futuro wrist orthosis with a synthetic ThermoLyn Orthosis: utility and clinical effectiveness. Arthritis Care Res. 1998; 11(3):217-22.

Vliet Vlieland TPM, Van Der Wijk TP, Jolie IM, Zwinderman AH, Hazes JM. Determinants of hand function in patients with rheumatoid arthritis. The Journal of Rheumatology. 1996; 23(5):835-40. PMid:8724294. 